\title{
SLOW MUSCLE FUNCTION OF PACIFIC BONITO (SARDA CHILIENSIS) DURING STEADY SWIMMING
}

\author{
D. J. ELLERBY ${ }^{1, *}$, J. D. ALTRINGHAM ${ }^{1}$, T. WILLIAMS ${ }^{2}$ AND B. A. BLOCK ${ }^{3}$ \\ ${ }^{1}$ School of Biology, The University of Leeds, Leeds LS2 9JT, UK, ${ }^{2}$ Monterey Bay Aquarium, 886 Cannery Row, \\ Monterey, CA 93940 and ${ }^{3}$ Tuna Research and Conservation Center, Hopkins Marine Station, Stanford University, \\ Pacific Grove, CA 93950, USA \\ *e-mail: bgydje@leeds.ac.uk
}

Accepted 5 April; published on WWW 13 June 2000

\begin{abstract}
Summary
The Pacific bonito, Sarda chiliensis, is anatomically intermediate between mackerel and tuna. The specialisations exhibited by tuna are present in the bonito, but to a lesser degree. Slow-twitch muscle strain and activity patterns were determined during steady swimming (tailbeat frequency $1.2-3.2 \mathrm{~Hz}$ ) at four locations on the body of Sarda chiliensis using sonomicrometry and electromyography. Both strain and the phase of electromygraphic activity were independent of tailbeat frequency. The strain of superficial slow-twitch muscle increased from $\pm 3.1 \% l_{0}$ at $0.35 F L$ to $\pm 5.8 \% l_{0}$ at $0.65 F L$,

relative to the strain cycle. Muscle activity patterns are comparable with those of tuna. At $0.58 F L$, the onset of activity in deep slow-twitch muscle was approximately synchronous with the onset of activity in superficial muscle in the same myotome at $0.65 \mathrm{FL}$. The distribution of slowtwitch muscle along the body of Sarda chiliensis and four additional fish species, Anguilla anguilla, Oncorhynchus mykiss, Scomber scombrus and Thunnus albacares, was also measured. Slow-twitch muscle appears to become more concentrated at approximately $0.5 F L$ as swimming kinematics become more thunniform.
\end{abstract} where $l_{0}$ is muscle resting length and $F L$ is the body length from snout to tail fork. Between 0.35 and $0.65 F L$, there was a negative phase shift of $16^{\circ}$ in the onset of electromygraphic activity in superficial slow-twitch muscle
Key words: swimming, Pacific bonito, Sarda chiliensis, electromyography, sonomicrometry, kinematics, muscle, strain.

\section{Introduction}

Most fish power swimming with their lateral musculature. Muscular contraction, the interactions between the fish and the water, and the mechanical properties of the passive components of the body combine to produce a wave of curvature that passes along the fish from head to tail. The body/tail wave generates net forward thrust. Lateral muscle fibres lengthen and shorten rhythmically during steady swimming. Patterns of muscle strain and activation show some variation both among species and with position along the body in a given species (Grillner and Kashin, 1976; Williams et al., 1989; van Leeuwen et al., 1990; Wardle and Videler, 1993; Johnson et al., 1994; Jayne and Lauder, 1995; Hammond et al., 1998). Studies of isolated muscle fibres from a number of fish species have shown that the phase relationship between strain and activation is crucial in determining how muscle functions (Altringham et al., 1993; Rome et al., 1993; Hammond et al., 1998; for reviews, see Wardle et al., 1995; Altringham and Ellerby, 1999).

The lateral musculature of all fish has a complex anatomy. Axially it is divided into a series of metamerically arranged myotomes. In fish, different muscle fibre types with distinct properties are usually arranged in discrete populations. This facilitates study of the function of different fibre types during locomotion. Low-tailbeat-frequency, sustained swimming is powered by slow-twitch aerobic muscle (e.g. Bone, 1966; Rayner and Keenan, 1967; Rome et al., 1992; Coughlin and Rome, 1999). Fast-twitch fibres are recruited during fast starts and bursts of high-tailbeat-frequency, unsustained swimming (e.g. Rayner and Keenan, 1967; Johnston et al., 1977). Patterns of muscle recruitment at intermediate speeds appear less clear (e.g. Bone, 1978; Brill and Dizon, 1979). There is considerable variation in the amount and placement of slow-twitch muscle in different groups. The relative proportions of slow-twitch and fast-twitch muscle appear to be related to lifestyle (Boddeke et al., 1959). Fish specialised for cruising tend to have relatively large amounts of slow-twitch muscle, whilst those with a more sedentary mode of life have little slow-twitch muscle and relatively large amounts of fast-twitch muscle. In most cases, the slow-twitch muscle is present as a wedge positioned beneath the lateral line. Some scombroid fish (Scombridae and Xiphiidae) differ from this pattern, having a portion of the slow-twitch muscle placed closer to the backbone (Fierstine and Walters, 1968; Westneat et al., 1993). This medial placement of the slow-twitch muscle is most pronounced in 


\section{D. J. ELLERBY AND OTHERS}

scombrid fish of the Thunnini tribe (Euthynnus, Auxis, Katsuwomus and Thunnus). The positioning of the slow-twitch muscle away from the body surface, coupled with the presence of countercurrent heat exchangers in the circulatory systems of some species, allows the temperature of the slow-twitch muscle mass to be maintained at a value well above the ambient water temperature. In the bluefin tuna Thunnus thynnus, the differential may be as high as $20^{\circ} \mathrm{C}$ (Carey and Lawson, 1973). This has important implications for locomotory performance by increasing muscle power output (Rome and Swank, 1992; Altringham and Block, 1997).

All scombrids are specialised in varying degrees for steady, sustained swimming (Magnuson, 1978). This is based on the presence of a range of morphological features. These include a body thickness to length ratio that is close to that required for minimum drag (Hertel, 1966), a rounded body profile, which increases swimming efficiency (Weihs, 1989), a lunate, high-aspect-ratio tail with a high lift to drag ratio (Lighthill, 1969) and a narrow caudal peduncle with lateral keels, which may maintain laminar flow in the region of the tail blade (Lighthill, 1969; Webb, 1975) and provide lift (Magnuson, 1973). Internally, there are features linked to efficient power transfer. The myotomes are highly elongated relative to those of other teleosts and contain large amounts of connective tissue. This connective tissue of the myosepts forms tendonlike structures that insert on the cones of the myotomes and the axial skeleton (e.g. Fierstine and Walters, 1968). The arrangement of the connective tissue is crucial in determining how force is transferred to the caudal region (Westneat et al., 1983). These adaptations may explain how yellowfin tuna achieve high locomotory efficiency relative to other teleosts (Dewar and Graham, 1994a).

Data on slow-twitch muscle function exist for three scombrid genera, a mackerel genus (Scomber) and two tuna genera (Thunnus and Katsuwonus). Tuna and mackerel lie at opposite ends of the spectrum of morphological, anatomical, physiological and kinematic variation displayed by the scombrids. Tuna differ in their patterns of muscle activity from other teleost species studied thus far. In most teleosts, there is a clear tendency for the onset of electromyographic (EMG) activity to occur progressively earlier in the muscle strain cycle, moving in a caudal direction along the fish (for reviews, see Gillis, 1998; Altringham and Ellerby, 1999). In the yellowfin (Thunnus albacares) and skipjack tuna (Katsuwonus pelamis), the tendency for a negative phase shift in muscle activity is largely absent (Shadwick et al., 1999). Patterns of muscle activity in mackerel have also been determined (Wardle and Videler, 1993; Shadwick et al., 1998). Mackerel show a clear negative shift in EMG activity to earlier in the strain cycle in the caudal region. This is the more typical teleost pattern.

The fish species for which data on muscle activity exist are highly diverse phylogenetically, anatomically and in terms of their swimming mode. This makes it difficult to draw meaningful conclusions about differences in muscle function. By comparing muscle function in related scombrid genera, confusion caused by phylogenetic disparities should be reduced, and a clearer picture of how muscle function and anatomy interact to produce swimming movements may emerge.

The ideal scombrid species to study would be one that represented a functional and phylogenetic intermediate between mackerel and tuna. Phylogenies based on molecular and morphological data suggest that the bonitos (genus Sarda) are closely related to the genera of tuna that exhibit systemic endothermy (Collette, 1978; Block and Finnerty, 1994). The specialisations exhibited by tuna are present in the bonito, but to a lesser degree. Bonito have some medial slow-twitch muscle, and a tendon arrangement intermediate between that of mackerel and tuna (Westneat et al., 1993). In terms of swimming function, the bonito may be similar to the immediate ancestors of tuna. Study of the bonito could provide important insights into the processes associated with the evolution of endothermy in this group. An understanding of its patterns of muscle strain and activation may suggest how the thunniform mode of locomotion evolved.

Using electromyography and sonomicrometry, we have determined the patterns of muscle strain and activity in freeswimming Pacific bonito (Sarda chiliensis). The distribution of slow-twitch muscle along the body has been quantified in a range of scombrids and non-scombrids as a means of further investigating changes in slow-twitch muscle function within the Scombridae. Differences in muscle distribution, muscle activity and connective tissue anatomy are related to differences in swimming mode.

\section{Materials and methods}

Bonito Sarda chiliensis (Cuvier) were caught off the coast of California in surface water temperatures of $17-20^{\circ} \mathrm{C}$. The fish were caught using lift poles with barbless hooks. They were held on board ship in seawater-filled wells before being transferred to a holding facility in San Diego, California. A specialised transport tank was used to transport the fish by road to the Tuna Research and Conservation Centre (TRCC) at Pacific Grove, California. All experiments were carried out at the TRCC, a joint facility of Hopkins Marine Station (Stanford University) and the Monterey Bay Aquarium. Fish were maintained at $20^{\circ} \mathrm{C}$ in a tank $6 \mathrm{~m}$ in diameter and $1.5 \mathrm{~m}$ in depth. Filtered and aerated sea water from Monterey Bay passed through the tank. The mean fork length $(F L)$ of the fish was $64.3 \pm 0.8 \mathrm{~cm}$ (range $60-71 \mathrm{~cm}$ ). Mean mass was $2.96 \pm 0.11 \mathrm{~kg}$ (range $2.50-3.99 \mathrm{~kg}$ ) (means \pm S.E.M., $N=10$ ). Sequences of swimming covered a range of tailbeat frequencies from 1.2 to $3.2 \mathrm{~Hz}$.

\section{Sonomicrometry and electromyography}

Electromyographic and sonomicrometry recordings were made from four points in the lateral slow-twitch muscle. These were the superficial slow-twitch muscle underlying the lateral line at $0.35,0.5$ and $0.65 F L$, where $F L$ is the body length from snout to tail fork, and a point deeper in the slow-twitch muscle where it extended to the backbone along the median horizontal septum. Superficial placements were at a depth of $5 \mathrm{~mm}$ below 


\section{Slow muscle function of Pacific bonito 2003}

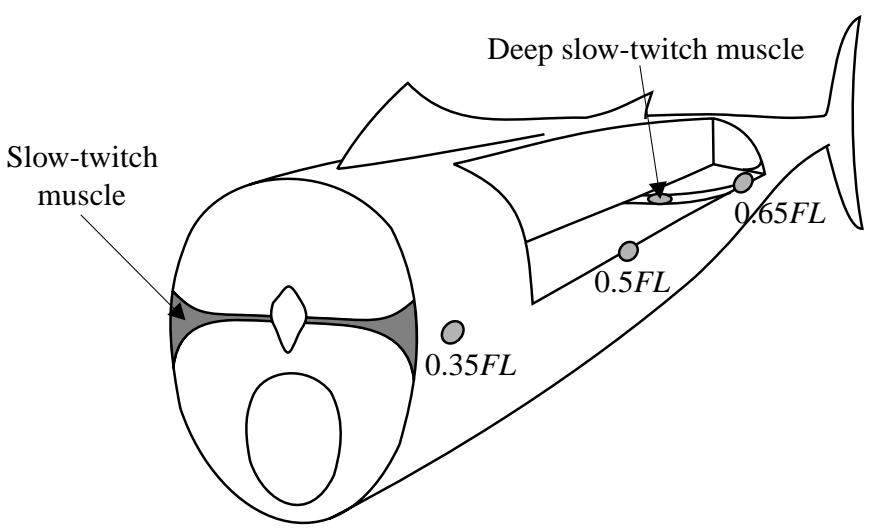

Fig. 1. Placement of sonomicrometry crystals and electromyographic (EMG) electrodes. Superficial placements are at $0.35,0.5$ and $0.65 F L$, where $F L$ is the body length from snout to tail fork. The left dorsal portion of the myotomal muscle is removed to a level just ventral to the main horizontal septum exposing the deep slow-twitch muscle placement at $0.58 F L$. This was in the same myotome as the superficial placement at $0.65 F L$.

the skin surface and on a straight line between the base of the pectoral fin and the caudal keel. The deep placement was located in the same myotome as the $0.65 F L$ superficial placement. The depth of placement in the deep slow-twitch muscle was $0.06 F L$ below the skin surface ( $38 \mathrm{~mm}$ in a $64 \mathrm{~cm} F L$ fish; Fig. 1). The entry point for the deep placement was at $0.58 F L$.

Sonomicrometry determines length changes from the transit time of an ultrasonic pulse between pairs of piezoelectric crystals. Measurements were made using a Triton Technologies model 120-1000 sonomicrometer. Calibration of the crystals was carried out by direct measurement in fresh water. The transmission speed of ultrasound is slightly faster in muscle $\left(1522-1572 \mathrm{~m} \mathrm{~s}^{-1}\right)$ than in water $\left(1500 \mathrm{~m} \mathrm{~s}^{-1}\right)$, so a small correction had to be made (Goldman and Richards, 1954; Moi and Breddels, 1982). Changes in muscle density during contraction have little effect on the velocity of ultrasound (Griffiths, 1987; Hatta et al., 1988). The disc-shaped crystals are directionally sensitive. To ensure a clear signal, the flat faces of crystal pairs need to be facing each other. Crystals were implanted via 19 gauge, 1.5 inch hypodermic needles. Pairs of needles were clamped together in the same plane and at the desired spacing to ensure correct alignment of the crystal pairs. All crystal leads and EMG electrodes were fitted with a $10 \mathrm{~mm}$ crossbar made from nylon monofilament fishing line. This was attached with epoxy resin. The crossbar was sutured to the skin to hold the wires in place and at the correct depth in the lateral muscle. The bars were arranged parallel to the face of the sonomicrometry crystals to indicate correct alignment.

An EMG electrode was implanted immediately adjacent to each pair of crystals. The entry point of the hypodermic needle was $5 \mathrm{~mm}$ dorsal to the position of the crystal pair. The needle track was angled ventrally so that the electrode tip was placed in the slow muscle mass $3 \mathrm{~mm}$ dorsal to the muscle tissue between the two crystals. The bipolar electrodes were constructed from $0.125 \mathrm{~mm}$ diameter Teflon-coated silver wire
(World Precision Instruments AGT 0510). The spacing of the recurved tips was $1.0 \mathrm{~mm}$. The exposed portions of the tips were $1.5 \mathrm{~mm}$ in length. EMG signals were filtered and amplified using a CED 1902 signal conditioner. Amplifier gain was set at 1000 for each channel. A $60 \mathrm{~Hz}$ notch filter was applied to remove mains interference. EMG data was filtered digitally using Spike 2 software to apply a $100 \mathrm{~Hz}$ high-pass filter and a $1500 \mathrm{~Hz}$ low-pass filter. The EMG electrodes and sonomicrometry crystals were linked to the preamplifiers by $9 \mathrm{~m}$ lengths of bathythermograph wire (Sippican Ocean Systems, Marion, MA, USA). All solder joints were cleaned with concentrated phosphoric acid prior to soldering. Phosphoric acid was also used as a flux in combination with a fluxless solder. All exposed solder joints were waterproofed using Dip-it Fantasy Film (Dip Film Products, UK).

Data channels were fed to a PC using a CED 1401plus A/D converter and interface card (Cambridge Electronic Design, UK). Data were recorded using Spike for Windows version 2.24. A $5 \mathrm{~ms}$ correction for phase delay must be applied during data analysis because of the active filtering of the Triton system.

\section{Surgical procedures}

Experimental animals were isolated from the other fish in the tank with vinyl crowders and captured in a water-filled vinyl sling. Whilst held in the sling, fish length was measured and a mass/length curve was used to estimate body mass. Fish were anaesthetised with a mixture of ketamine at a dosage of $4 \mathrm{mg} \mathrm{kg}^{-1}$ body mass and medetomidine at a dosage of $0.4 \mathrm{mg} \mathrm{kg}^{-1}$ body mass. Each drug was administered by intramuscular injection into the slow-twitch muscle posterior to the base of the pectoral fin. After surgery, a recovery dose of atipamezole was administered by the same method, at a dosage of $2 \mathrm{mg} \mathrm{kg}^{-1}$. Surgery was carried out on a raised, padded platform in the tank. The gills were perfused with oxygenated sea water using a submersible pump at a flow rate of $21 \mathrm{~min}^{-1}$. The duration of surgery ranged from approximately 10 to $25 \mathrm{~min}$. Prior dissection had established the desired placements for the crystals and EMG electrodes in the slow-twitch muscle. It had been found that the slow-twitch muscle fibres were aligned parallel to the body axis at all the measurement points used in the experiments. The pectoral fin, tail keel and lateral line were used as external markers to indicate correct placement during surgery. All suturing was carried out using PDS II (Ethicon Inc., Somerville, NJ, USA) and an FS-2 cutting needle. Fish were killed at the conclusion of each experiment by decapitation and pithing. Crystals and electrodes were dissected out to establish whether they had been correctly aligned with the muscle fibres. Points where alignment of the crystals was greater than $10^{\circ}$ out of line with the fibre long axis were excluded from the analysis.

\section{Video recording and kinematic analysis}

Experiments were recorded using a Canon EX2 Hi-8 video camera with a wide-angle lens. This was mounted above the tank. The field of view was approximately $3.0 \mathrm{~m} \times 2.5 \mathrm{~m}$. 
Sequences of undisturbed, steady swimming for 10 wired and 10 unwired fish were selected at random for analysis. Sequences in which the final trajectory of the fish differed from its initial trajectory by more than $10^{\circ}$ after three tailbeats were not used for analysis. An ATI All-in Wonder Pro video card and software were used to grab video frames for kinematic analysis. Frames were grabbed at a resolution of 640 pixels $\times 480$ pixels. This meant that measurements could be made to an accuracy of approximately $5 \mathrm{~mm}$. The frame rate of $50 \mathrm{~Hz}$ gave a time resolution of $0.02 \mathrm{~s}$. Measurements were made from still frames using Sigma Scan Pro image-analysis software. Cartesian coordinates were recorded at seven points along the length of the fish. These were the snout, the posterior base of each pectoral fin, the rear of the second dorsal fin, the tip of each tail keel and the tip of the tail. Mid-points were calculated for the pairs of points at the pectoral fin bases and keel tips. The displacements of these points through time were used to calculate stride length, propulsive wavelength, yaw and tailbeat amplitude. Because the lengths of all fish were not known, all measurements are expressed as a proportion of the body length $(B L)$. Total body length is used rather than fork length $(F L)$ because, when viewed from above, the tail fork is not visible. In bonito, the fork of the lunate tail is not deep, so the difference between $F L$ and $B L$ is small $(2-3 \mathrm{~cm}$ for a $70 \mathrm{~cm}$ fish).

Stride length is the distance moved by a fish during a tailbeat cycle. Measuring the time between peak lateral displacement of successive points of known separation on the body allows the velocity of the propulsive wave along the body to be calculated. This parameter can be used to estimate the propulsive wavelength (propulsive wavelength $=$ propulsive wave velocity/tailbeat frequency). The yaw is the amplitude of the lateral displacement of the snout, and tailbeat amplitude is the amplitude of the lateral displacement of the tail tip. A statistical comparison was made between these parameters for wired and unwired fish to determine whether implantation of the sensors affected swimming kinematics.

\section{Distribution of slow-twitch muscle along the body}

Transverse sections were made of three scombrids; bonito, Atlantic mackerel (Scomber scombrus) and yellowfin tuna (Thunnus albacares) at $0.1 F L$ intervals. Two non-scombrid species, the eel Anguilla anguilla and the trout Oncorhynchus mykiss, were similarly sectioned. Each section was photographed using a Nikon E3s, or Sony Mavica, digital camera. Absolute cross-sectional areas of slow-twitch and fasttwitch muscle were measured using Sigma Scan Pro software. To allow clear comparison among species, muscle areas were also expressed as a proportion of the amount of muscle at $0.5 F L$.

Fifth-order polynomial functions were fitted to the curves of cross-sectional area and slow-twitch muscle area. By integrating these functions and calculating the areas under the curves, estimates of total muscle volume and slow-twitch muscle volume were made for each species. Slow-twitch muscle volume was expressed as a proportion of total muscle volume for each species.

\section{Statistical analyses}

Sigma Stat (SPSS, Chicago, IL, USA) software was used for statistical analyses. The kinematic parameters of wired and unwired fish were compared using a Student's $t$-test. A Pearson product moment correlation was used to test for any relationships between strain and phase of activation and tailbeat frequency. A two-way analysis of variance (ANOVA) was used to test for significant differences in strain and phase of activation between different points in the slow-twitch muscle and between different fish. All results are expressed as mean \pm S.E.M. with the number of observations given in parentheses.

\section{Results \\ Kinematics}

There were no significant differences between the kinematic parameters measured for wired and unwired fish $(P>0.05)$ (Table 1). The mean speed of the wave of body curvature $(V)$ passing caudally along the body was $1.28 \pm 0.04 B L T^{-1}(N=20)$, where $T$ is the duration of one complete tailbeat.

\section{Strain patterns}

There was no significant relationship between strain amplitude and tailbeat frequency $(P=0.32)$ (Fig. 2). Fourier analysis confirmed that the strain cycle approximated a sine wave: more than $95 \%$ of the spectral power appeared in the first harmonic. For this reason, the cycle was described by a sine wave where resting length $l_{0}$ is at $0 / 360^{\circ}$, peak strain is at $90^{\circ}$ and minimum length is at $270^{\circ}$. The mean speed of the strain wave passing caudally along the body was $1.34 \pm 0.04 F L T^{-1}(N=20)$, where $T$ is the duration of one complete tailbeat.

A two-way ANOVA showed that there were significant differences in muscle strain at different positions on the body $(P=0.013)$. For a given body position, differences between fish were not significant $(P=0.11)$. Strain was recorded as the percentage change in resting muscle fibre length $\left( \pm l_{0}\right)$. Mean muscle strains for results pooled from each body position are $\pm 3.1 \pm 0.08 \% l_{0}$ at $0.35 F L, \quad \pm 5.2 \pm 0.07 \% l_{0}$ at $0.5 F L$, $\pm 5.8 \pm 0.08 \% l_{0}$ at $0.65 F L$, all in the superficial slow-twitch

Table 1. Summary of kinematic parameters for wired and

\begin{tabular}{lccc}
\multicolumn{4}{c}{ unwired fish } \\
\\
\hline Wired & Unwired & $P$ \\
\hline Stride length & $0.75 \pm 0.03$ & $0.77 \pm 0.03$ & 0.76 \\
Mechanical wavelength & $1.07 \pm 0.07$ & $1.13 \pm 0.06$ & 0.94 \\
Tailbeat amplitude & $0.19 \pm 0.01$ & $0.21 \pm 0.02$ & 0.66 \\
Yaw & $0.05 \pm 0.01$ & $0.05 \pm 0.01$ & 0.89
\end{tabular}

Values are means \pm S.E.M. $(N=10)$.

All measurements are expressed as a proportion of total body length $(B L)$.

Probability values are those returned by a Student's $t$-test used to compare the kinematic parameters of wired and unwired fish. 
Fig. 2. Muscle strain in relation to tailbeat frequency. Strain was recorded as the percentage change in resting muscle fibre length $\left( \pm l_{0}\right)$. Values from different fish are shown by different symbols. Values for superficial muscle at $0.35, \quad 0.5, \quad 0.65 F L$, where $F L$ is the body length from snout to tail fork, and for deep slow-twitch muscle at $0.58 F L$ are shown by blue, red, green and black symbols, respectively.

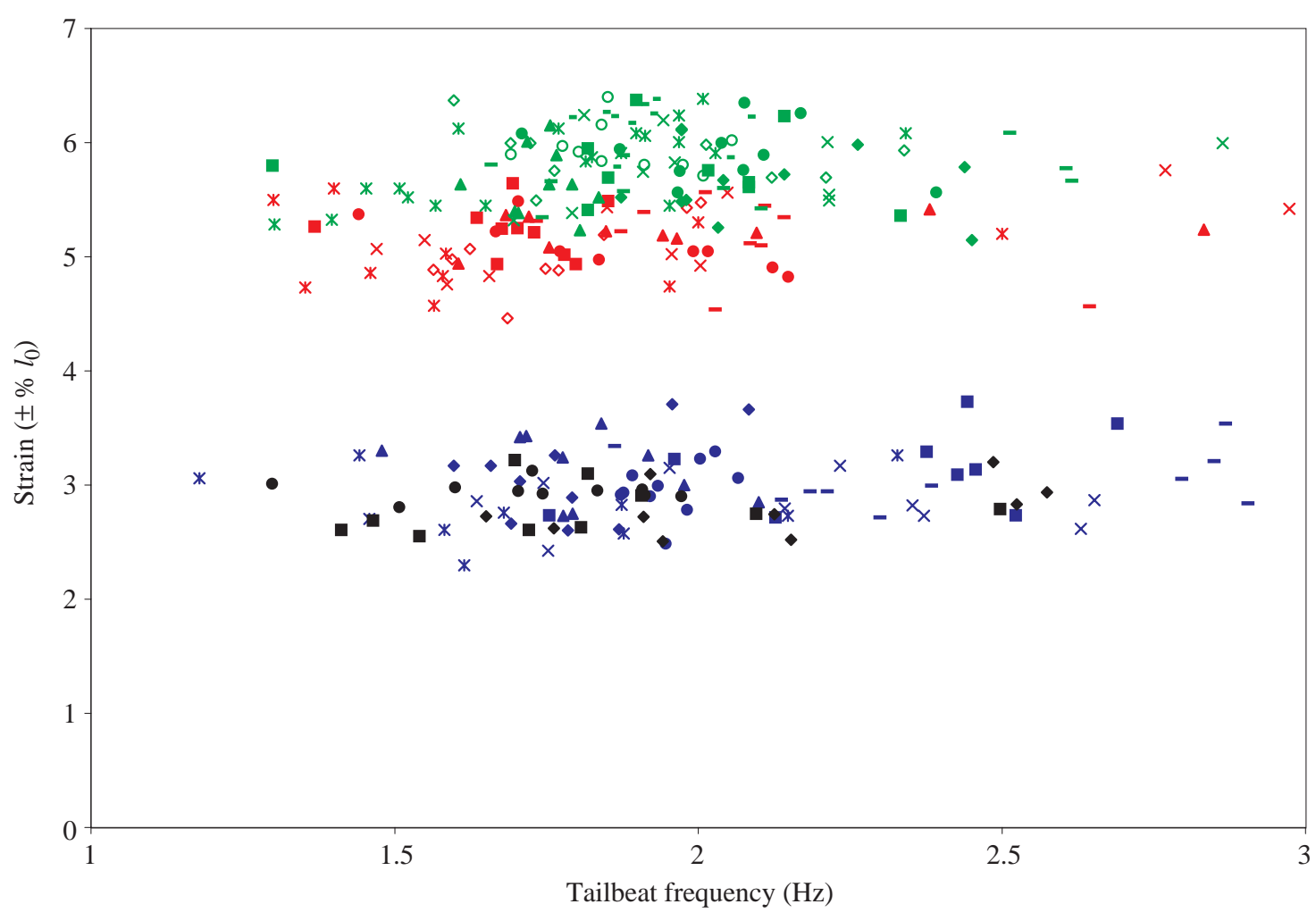

muscle, and $\pm 2.8 \pm 0.12 \% l_{0}$ in the deep slow-twitch muscle at $0.58 F L$.

\section{Phase of activity}

There was no significant relationship between phase of EMG activity and tailbeat frequency $(P=0.25)$ (Fig. 3). A twoway ANOVA detected significant differences in the phase of EMG onset relative to the strain cycle at different positions on the body $(P=0.019)$. For a given body position, there was no significant difference in phase of EMG onset among different individuals. There was a small, but statistically significant, negative shift in the onset of EMG activity relative to the strain cycle moving in a caudal direction along the fish (Table 2). The mean speed of the wave of EMG onset passing caudally along the body was $1.66 \pm 0.04 F L T^{-1}(N=20)$.

The duration of EMG activity decreases posteriorly along the fish. Longer anterior EMG duration results in later offset times relative to the strain cycle in the anterior of the fish than in the posterior.

The EMG electrode in the superficial muscle at $0.65 F L$ and the deep slow-twitch muscle EMG electrode were placed in the same myotome. The time of EMG onset at these two points was measured relative to a 'time zero' when the muscle at $0.35 F L$ was at $l_{0}$ whilst lengthening. A two-way ANOVA showed that there was no significant difference in EMG onset timing at these two positions or among different fish at a given position $(P=0.57)$ (Fig. 4).

\section{Distribution of slow-twitch muscle}

A myotome consists of several hollow cones of muscle
Table 2. Mean onset and offset times of electromyographic activity relative to the sinusoidal, $360^{\circ}$, strain cycle

\begin{tabular}{lcc}
\hline Position & $\begin{array}{c}\text { EMG onset } \\
\text { (degrees) }\end{array}$ & $\begin{array}{c}\text { EMG offset } \\
\text { (degrees) }\end{array}$ \\
\hline Superficial slow-twitch muscle & & \\
$\quad 0.35 F L$ & $52.9 \pm 0.8(70)$ & $209.7 \pm 0.9(70)$ \\
$0.5 F L$ & $45.9 \pm 1.0(50)$ & $180.2 \pm 1.2(50)$ \\
$0.65 F L$ & $36.8 \pm 0.8(80)$ & $159.5 \pm 0.8(80)$ \\
Deep slow-twitch muscle & $58.5 \pm 2.4(30)$ & $182.4 \pm 3.2(30)$
\end{tabular}
$0.58 F L$

Values are means \pm S.E.M. $(N)$.

$F L$ is fork length.

Muscle is at resting length $l_{0}$ at $0^{\circ}$.

Data represent pooled results from a number of individuals.

tissue the apices of which are directed both anteriorly and posteriorly. The hollow cones of successive myotomes are nested within each other. The relative extent of elongation of the myotomes can be assessed by counting the number of nested cones cut across in a body cross section. The anteriorpointing cones of the myotomes of Sarda chiliensis are less highly nested than in tuna, but more so than those of the mackerel. In Sarda chiliensis, the anterior-pointing cones of eight myotomes are cut across in each quadrant of the cross section; this compares with six in Scomber scombrus and 12 in Thunnus albacares. In addition to differences in myotomal anatomy, there are differences in slow-twitch muscle distribution within the myotome. Scomber scombrus displays 


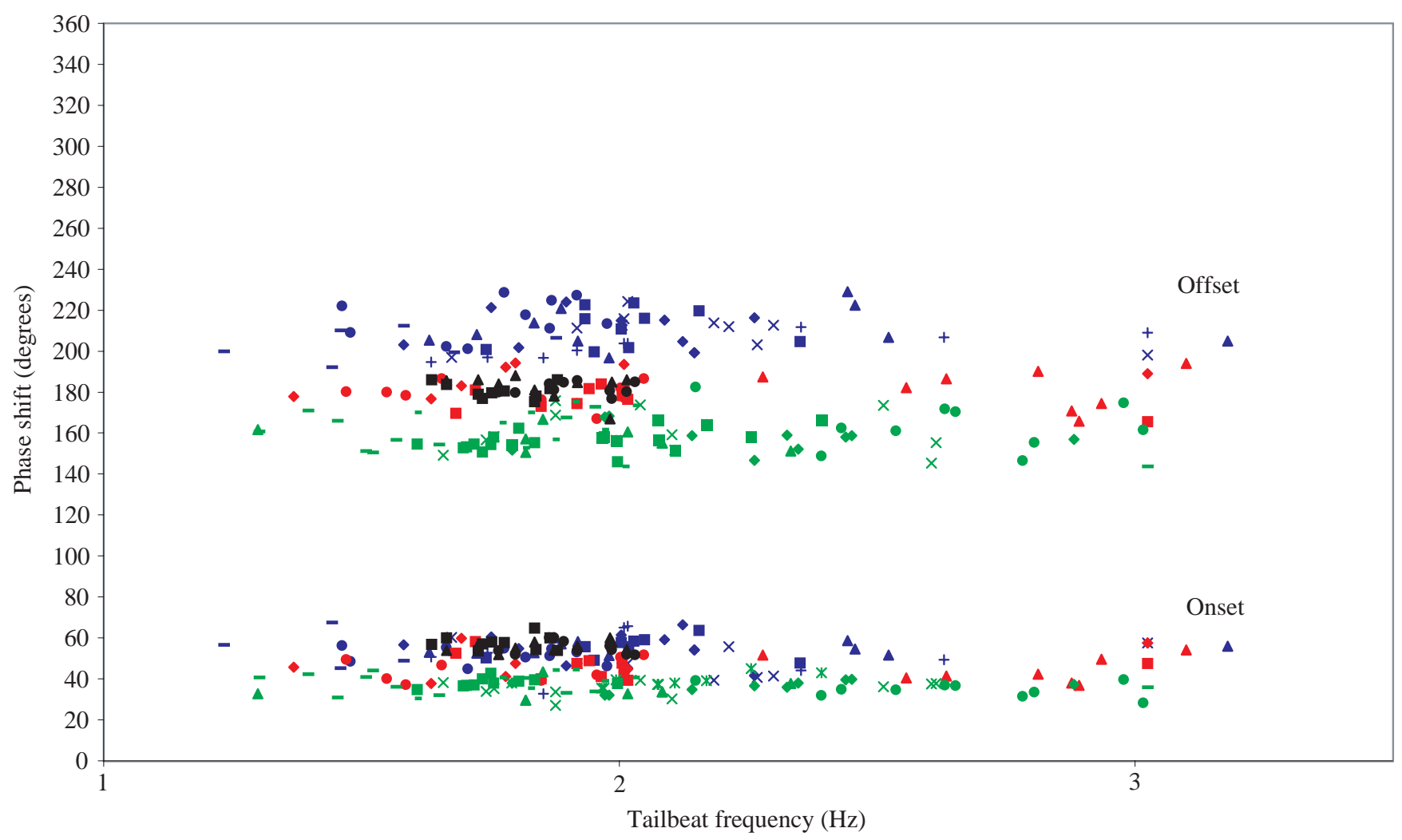

Fig. 3. Phase of electromyographic (EMG) onset and offset within the strain cycle in relation to tailbeat frequency. Values from different fish are shown by different symbols. Values for superficial muscle at $0.35,0.5,0.65 F L$ and for deep muscle at $0.58 F L$, where $F L$ is the body length from snout to tail fork, are shown by blue, red, green and black symbols respectively. There was no correlation between tailbeat frequency and phase of EMG onset or offset.

the typical teleost slow-twitch muscle distribution with a wedge of slow-twitch muscle underlying the lateral line. In Sarda chiliensis, the region of slow-twitch muscle fibres extends all the way from the lateral line to the backbone. In Thunnus albacares, the slow-twitch muscle similarly extends to the backbone, but a greater proportion of the slow-twitch muscle is placed medially (Fig. 5).

Estimates of slow-twitch muscle volume as a percentage of total muscle volume between 0.3 and $0.8 F L$ were $11 \%$ in Scomber scombrus, $16 \%$ in Sarda chiliensis, $10 \%$ in Thunnus albacares, $3 \%$ in Oncorhynchus mykiss and $13 \%$ in Anguilla anguilla. In Thunnus albacares and Sarda chiliensis, there is a clear peak in slow-twitch muscle cross-sectional area at $0.5 F L$, but the peak is broader in Sarda chiliensis and proportionally more slow-twitch muscle is found in the posterior of the body (Fig. 6). In Scomber scombrus, the peak is broader still, but it is still located at around $0.5-0.6 F L$. Oncorhynchus mykiss shows a posterior shift in peak slowtwitch muscle placement. The pattern is very different in Anguilla anguilla, in which the slow-twitch muscle is evenly distributed between 0.4 and $0.7 B L$.

\section{Discussion}

Muscle activity

There is a small $\left(16^{\circ}\right)$, but statistically significant negative shift in the onset of electrical activity relative to the strain cycle moving caudally along the length of the bonito. This occurs because the speed of propagation of the wave of EMG onset is greater than the speed of the muscle strain wave. This is comparable with the pattern seen in the skipjack tuna (Shadwick et al., 1999) (Fig. 7). The phase shift is much smaller than that seen in Atlantic and Pacific mackerel (Wardle and Videler, 1993; Shadwick et al., 1998). A shift in the phase of muscle activity relative to the strain cycle is not confined to axial, aquatic locomotion in fish, but occurs in a wide range of organisms and situations, e.g. in terrestrial locomotion in the eel Anguilla rostrata (Gillis, 2000), in undulatory, pectoral fin locomotion in the stingray Taenuria lymma (Rosenberger and Westneat, 1999), in snake swimming (Jayne, 1988) and in salamander swimming (Frolich and Biewener, 1992). A substantial negative phase shift, where present, may suggest a change in muscle function along the length of the body. In saithe, trout and scup, this pattern of activation results in a larger negative work component during the strain cycle in caudal muscle and enhanced muscle stiffening, although net power production is still positive. It has been suggested that, in the absence of substantial tendons, this may aid power transmission from the anterior of the fish to the tail region. This is presumably an inefficient means of power transmission compared with tendon; however; it allows the fish to maintain flexibility in its tail region, therefore maintaining a high level 


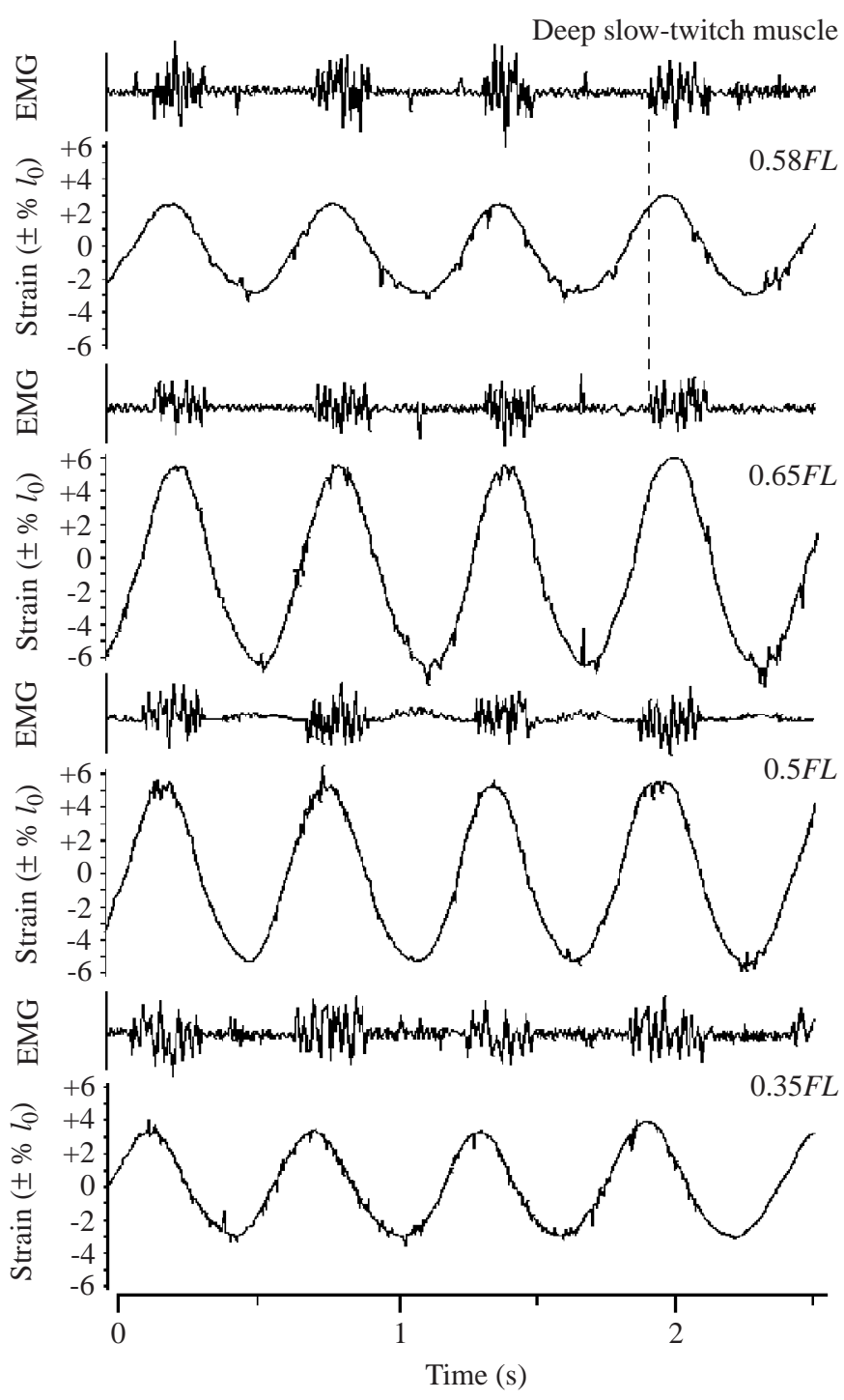

Fig. 4. Sonomicrometry and electromyographic (EMG) recordings for a sequence of three steady tailbeats at a tailbeat frequency of $1.7 \mathrm{~Hz}$. The vertical dashed line highlights the apparently synchronous onset of EMG activity in slow-twitch muscle at two points within the same myotome but at different locations along the body axis. $F L$ is the body length from snout to tail fork.

of manoeuvrability compared with thunniform fish (for a review, see Wardle et al., 1995). In the bonito and the tunas, where a phase shift in the activation of muscle along the body is less apparent, the tendons are likely to play a greater role in power transmission.

EMG duration decreases caudally. This decrease in EMG duration is present in all teleosts for which EMG data exist, except anguilliform swimmers. The onset of EMG activity occurs during muscle lengthening, just prior to maximum length, at all points along the body. EMG activity then persists well into the shortening phase. This onset of muscle activity in the lengthening phase has been shown to enhance muscle force and power production during the subsequent shortening phase (e.g. Altringham and Johnston, 1990). Altringham and Block (1997)
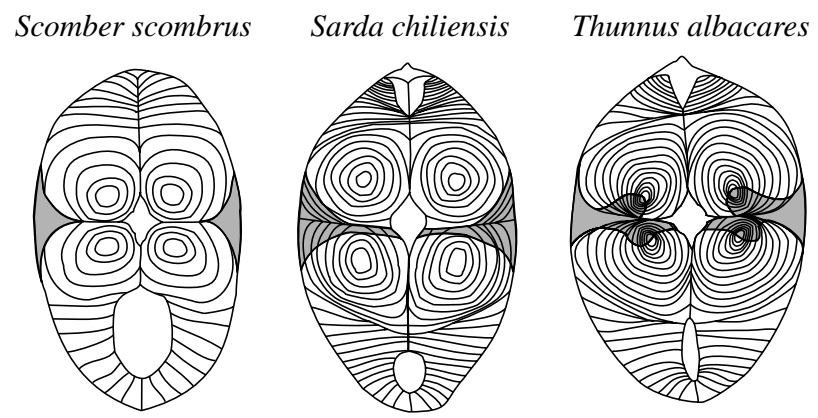

Fig. 5. Cross sections of Atlantic mackerel (Scomber scombrus), bonito (Sarda chiliensis) and yellowfin tuna (Thunnus albacares) at $0.5 F L$, where $F L$ is the body length from snout to tail fork. Shaded areas denote slow-twitch muscle.

used an in vitro onset of activation increasing from 20 to $60^{\circ}$ between 15 and $30^{\circ} \mathrm{C}$ to optimise power production in Sarda chiliensis slow-twitch muscle. The onsets of activation observed for bonito $\left(37-53^{\circ}\right)$ lie within this range of values. This suggests that in vivo the slow-twitch muscle is operating close to the optimal phase of activity for maximising power production.

Surprisingly, the question of whether muscular activity progresses along the body from myotome to myotome or whether activity progresses by longitudinal position has not been resolved. Jayne and Lauder (1995) found that in fast muscle the myotome appeared to be the functional unit in terms of muscle activation. The onset of activity in bonito deep slowtwitch muscle occurs at the same time as the onset of activity in the superficial slow-twitch muscle of the same myotome. This supports the idea of sequential activation of myotomes rather than activation of muscle at the same axial position. This is in contrast with the findings of Knower et al. (1999), who suggest that in tuna a given axial position on the body is activated, rather than a given myotome. Knower et al. (1999) did not obtain sufficient data to completely rule out whole myotome recruitment in tuna. Without further EMG studies, it is impossible to establish whether the progression of muscular activation proceeds along the body differently in tuna compared with other teleosts.

\section{Muscle strain}

Shadwick et al. (1999) found in skipjack tuna (Katsuwonus pelamis) that deep local muscle shortening was not in phase with local body curvature and that strain increased from $\pm 5.4 \%$ at $0.41 F L$ to $\pm 8.2 \%$ at $0.69 F L$. Deep muscle strain in the bonito at $0.58 F L$ was much lower than this $( \pm 2.8 \%)$. This may be due to differences in swimming style and the site of placement of strain gauges within the myotome. The superficial muscle strain in Pacific mackerel (Scomber japonicus) calculated from midline curvature was $\pm 6.3 \%$ at $0.43 F L$, increasing to $\pm 8.7 \%$ at $0.75 F L$ (Shadwick et al., 1998). Superficial muscle strains in bonito ranged from $\pm 3.1 \%$ at $0.35 F L$ to $\pm 5.8 \%$ at $0.65 F L$. The most anterior sampling point in bonito lies in a region of the body that undergoes relatively little bending during swimming, and low superficial strains are to be expected. 


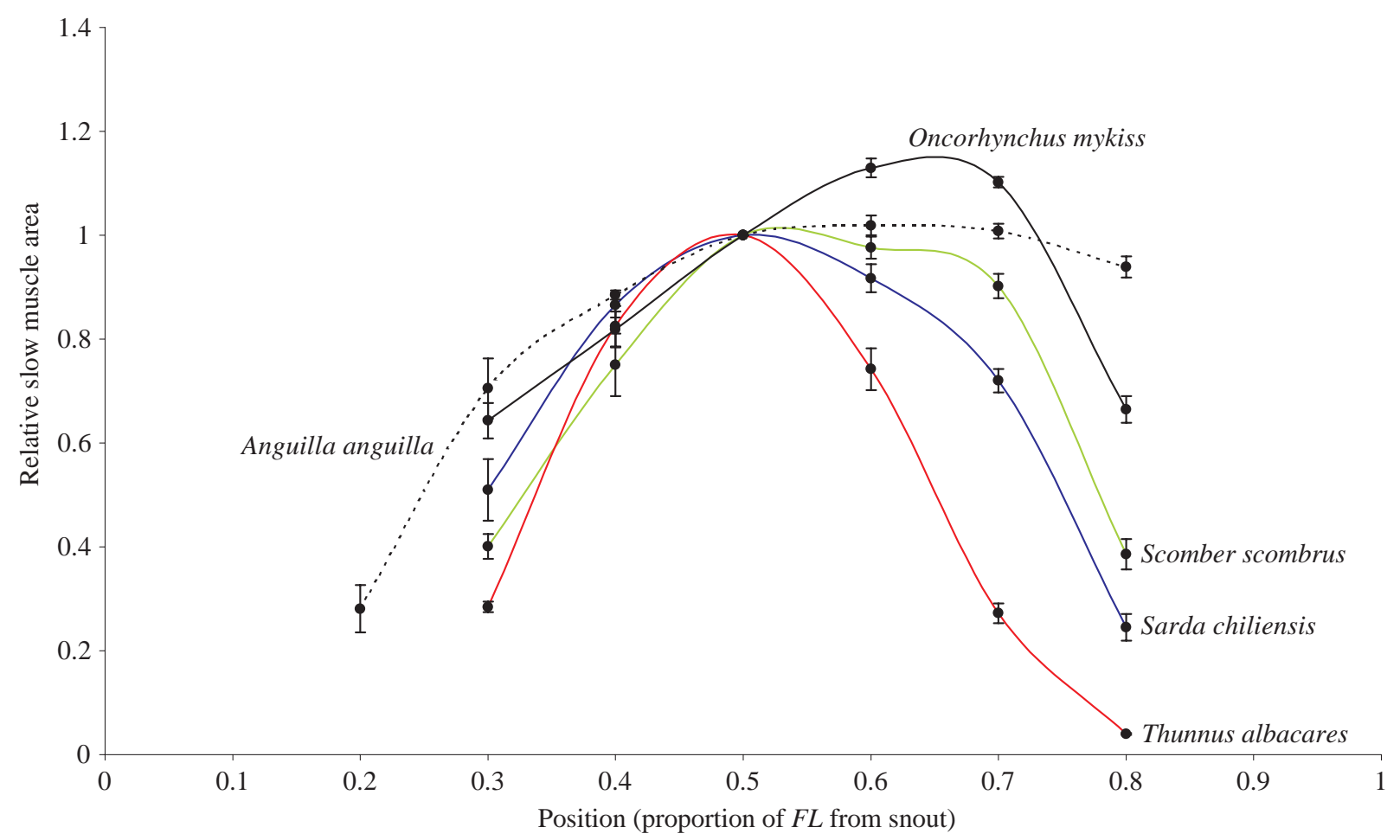

Fig. 6. Distribution of slow-twitch muscle along the body of five teleost fish species, Thunnus albacares, Sarda chiliensis, Scomber scombrus, Oncorhynchus mykiss and Anguilla anguilla. Muscle cross-sectional area is shown as a proportion of the slow-twitch muscle area at $0.5 F L$ for each species, where $F L$ is the body length from snout to tail fork. Values are means \pm S.E.M. $(N=4)$.

Fig. 7. Changes in the relationship between electromyographic (EMG) activity and strain cycle along the body of four scombrid species. EMG timing data are derived from Shadwick et al. (1999; Katsuwonus pelamis), Shadwick et al. (1998; Scomber japonicus) and Wardle and Videler (1993; Scomber scombrus). FL is the body length from snout to tail fork.
Anterior muscle

Posterior muscle

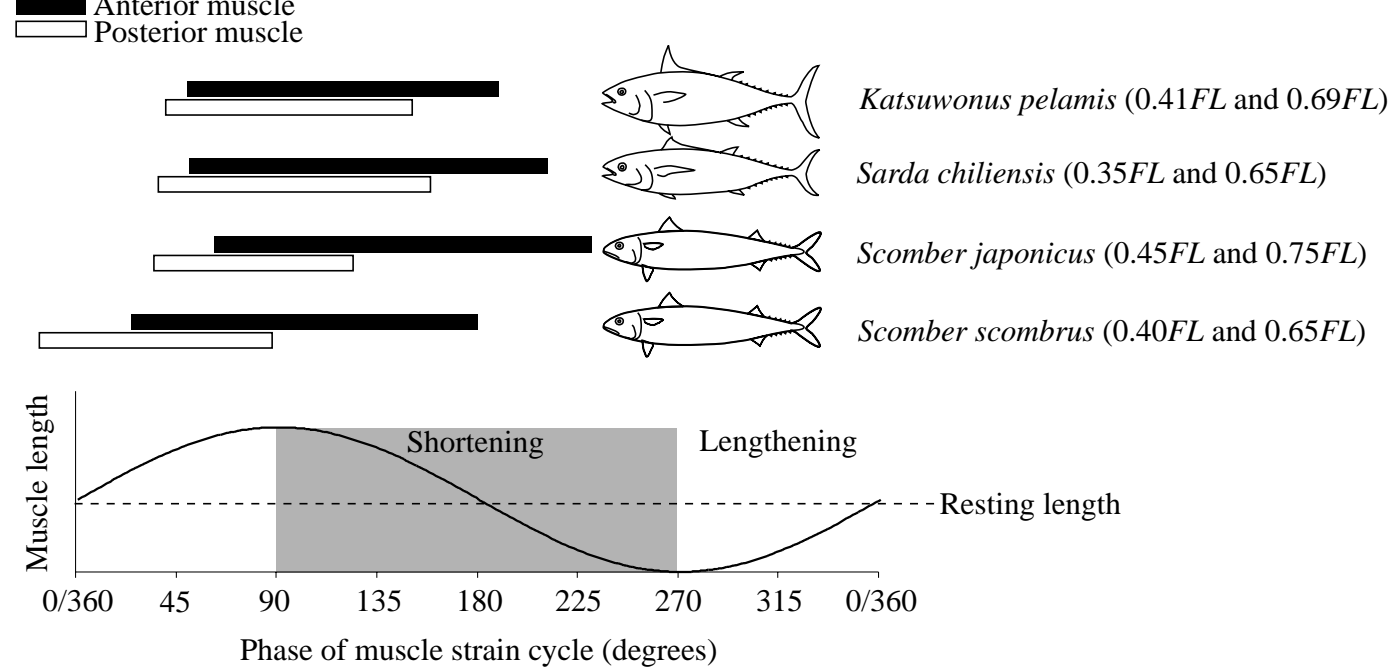

\section{Kinematics}

Swimming kinematic parameters are apparently unaffected by the implantation of crystals and electrodes (see Table 1). The mechanical wavelength of the bonito (1.1) is intermediate between that of the mackerel Scomber scombrus (1.00; Wardle and Videler, 1993) and the yellowfin tuna Thunnus albacares (1.23-1.29; Dewar and Graham, 1994b). The mean stride length $(U=0.76)$ lies within the range measured for other scombrids. Videler and Hess (1984) found a stride length range of 0.74-1.04 in the Atlantic mackerel Scomber scombrus. In tuna, the stride length ranged from 0.54 to 0.93 in the bluefin tuna Thunnus thynnus (Wardle et al., 1989) and from 0.4 to 0.7 in Thunnus albacares (Dewar and Graham, 1994b). The value is similar to that $(0.79)$ previously measured in the bonito by Altringham and Block (1997). The amount of yaw (0.05) is at the upper end of the range seen in Thunnus albacares (0.023-0.05; Dewar and Graham, 1994b). The envelope of lateral displacement is similar to that of Scomber scombrus (Fig. 8). Lateral undulation is mainly confined to the posterior two-thirds of the body, in contrast to tuna, in which lateral 
Fig. 8. Peak lateral body deflection of three scombrid species. Bonito Sarda chiliensis, Atlantic mackerel Scomber scombrus and yellowfin tuna Thunnus albacares are represented by thick, dashed and thin dotted lines, respectively. Data points for bonito and yellowfin are fitted with fourth-order polynomial regression lines. Data for Scomber scombrus are derived from Wardle and Videler (1993). Data for Thunnus albacares are derived from Fig. 3C in Dewar and Graham (1994b). BL is total body length. Values for bonito are means \pm S.E.M. $(N=10)$.

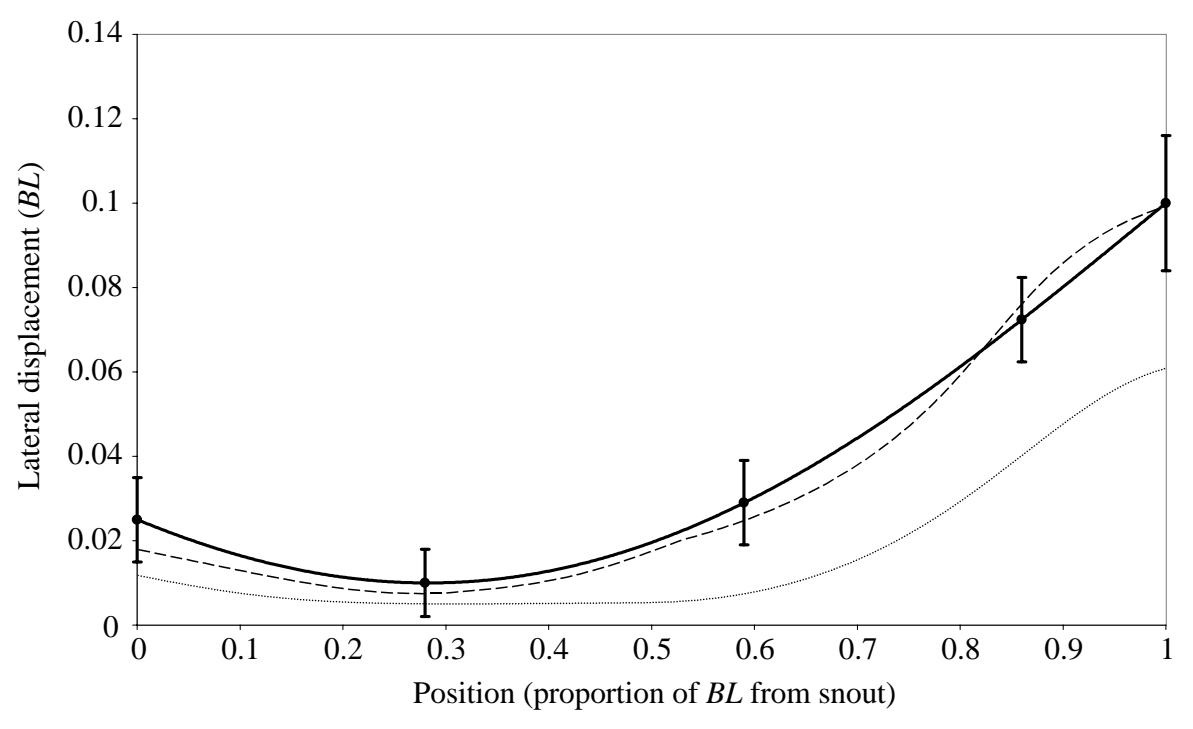

albacares as a percentage of body mass were 4.51, 6.22 and 6.51 respectively. On this basis, Sarda chiliensis appears to have relatively less slow-twitch muscle than these other scombrids, although rather wide confidence intervals suggest that the differences are not significant. When considering the estimated volume of slow-twitch muscle in the $0.3-0.8 F L$ region as a proportion of total lateral muscle volume in this region, bonito appear to have a greater proportion of slowtwitch muscle than either yellowfin tuna or Atlantic mackerel. This is only an estimate, but it suggests that caution should be exercised when making comparisons of muscle amounts among different species. The relative slow-twitch muscle volume of scombrids (10-16\%) appears to be greater than that of some other teleosts. The volume of lateral muscle occupied by slow-twitch muscle is only $5 \%$ in saithe (Videler, 1985) and $3 \%$ in trout. The volume found in scombrids is comparable with that found in the eel Anguilla anguilla. This suggests that the possession of a relatively large amount of slow-twitch muscle is not confined to active, pelagic fish. In fact, in scombrids in which systemic endothermy is well developed, we might expect to see a decline in slow-twitch muscle volume relative to that in ectothermic scombrids with similar power requirements. This is because slow-twitch muscle power output would be increased at elevated temperatures.

\section{Trends in scombrid evolution}

Graham et al. (1983) indicate that there are large differences in the distribution of slow-twitch muscle along the body in different scombrid groups. In their study, the position of the maximum amount of red muscle $\left(R_{\max }\right)$ in carangiform swimmers (bonito and mackerel) coincides with the position of maximal body flexure $(0.7 F L$ as identified by Greer-Walker and Pull, 1975). In tuna. $R_{\max }$ was found to be much farther forward at $0.4-0.5 F L$. This clear difference is a consequence of expressing the amount of slow-twitch muscle as a percentage of cross-sectional area rather than in absolute terms. In the three scombrid species for which measurements were

made in the present study, the position of absolute maximum
Graham et al. (1983) found that the slow-twitch muscle masses of Sarda chiliensis, Scomber japonicus and Thunnus 

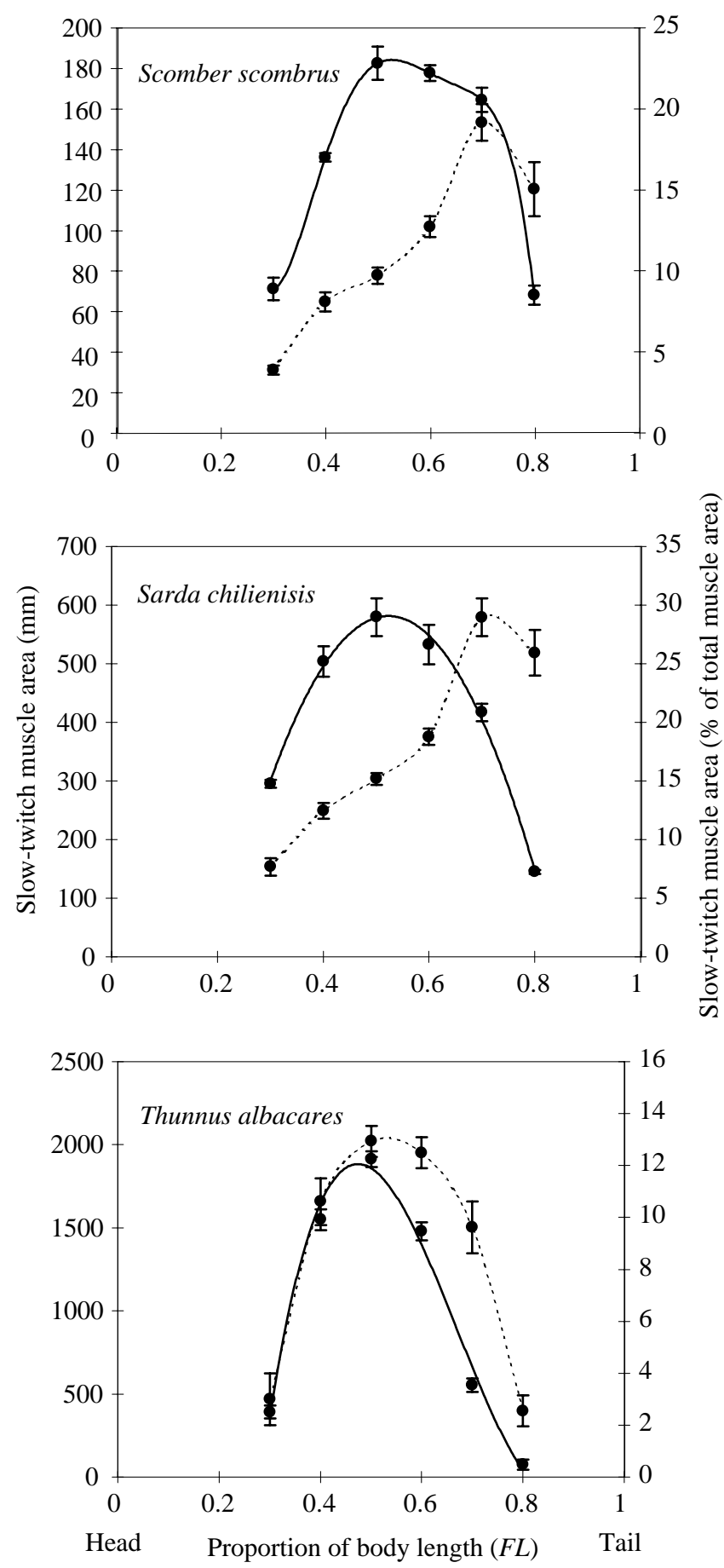

Fig. 9. Distribution of slow-twitch muscle along the body of three scombrid species. The solid lines show absolute muscle area, and the dashed lines show muscle area as a percentage of total muscle crosssectional area. Data points are fitted with fourth-order polynomial regression lines. $F L$ is the body length from snout to tail fork. Values are means \pm S.E.M. $(N=4)$.

red muscle cross-sectional area was approximately the same in all cases (0.5FL, Fig. 9).

In mackerel, slow-twitch muscle is relatively evenly distributed along the central portion of the body from 0.4 to
$0.7 F L$. In tuna, the amount of slow-twitch muscle decreases markedly posterior to $0.5 F L$. The bonito shows a pattern intermediate between these. The distribution of slow-twitch muscle in non-scombrid fish that swim in more undulatory modes suggests the existence of a trend that is related to function rather than phylogenetic relationships. In the trout Oncorhynchus mykiss, a subcarangiform swimmer, a broad peak in the amount of slow-twitch muscle occurs at 0.6-0.7FL. In the eel Anguilla anguilla, slow-twitch muscle is more evenly distributed along the body. Differences in the distribution of slow-twitch muscle along the body suggest a localisation in the main site of power production as scombrids, and perhaps fish in general, become more specialised for thrust generation by the caudal fin. Differences in the pattern of slow-twitch muscle distribution are probably related to the method of power transmission from the site of power production to the site of thrust generation and to the way in which thrust is transferred to the water. It appears that there may be a trend towards concentration of the majority of the slow-twitch muscle in a discrete region of the body that is linked to the caudal region by connective tissue. The substantial amount of connective tissue present in the median horizontal septum is probably the main route of power transmission in scombrids. Efficient power transmission is critical in scombrids, particularly tuna, in which virtually all thrust is developed at the caudal fin (Lighthill, 1975). The most efficient way for a fish to oscillate a posterior caudal fin would be via a single muscle positioned on each side of the body, each muscle being linked to the caudal region by a single tendon. In essence, this would be rather like the arrangement of antagonistic muscles around a quadruped limb joint. This condition can never be achieved in fish because of some major functional and anatomical constraints. A fish has to perform manoeuvres other than straight-line, steady swimming. In tuna, this capability is reduced relative to other teleosts (Blake et al., 1995). A metamerically segmented musculature imposes limits on the concentration of slow-twitch muscle into a single unit, and a similarly segmented nervous system produces a wave of muscle activation passing along the body.

If the analogy with an antagonistic pair of muscles acting on a joint is extended to include muscle activation patterns, then ideally all parts of the slow-twitch muscle would be activated almost simultaneously, and antagonistic, contralateral muscles would not be activated at the same time. One would expect to see a particularly rapid wave of EMG activity in tuna relative to other fish and little, if any, overlap in contralateral slowtwitch muscle activity. There is some evidence for a higher speed of EMG propagation in relatively stiff-bodied swimmers such as tuna and bonito compared with more undulatory swimmers such as trout and eel (Table 3). Fig. 10 shows EMG activity relative to the tailbeat cycle for a range of species. There appears to be a trend for decreasing overlap of contralateral EMG activity moving from the anguilliform mode of swimming through to the thunniform mode. In Sarda chiliensis, Katsuwonus pelamis and Thunnus albacares, there is no overlap in contralateral EMG activity, and in Scomber 


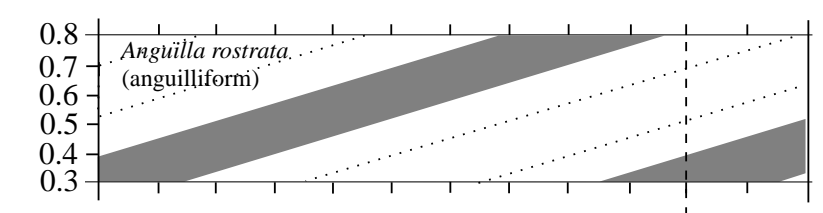

$\begin{array}{lllllllllllll}0.5 & 0.6 & 0.7 & 0.8 & 0.9 & 1.0 / 0 & 0.1 & 0.2 & 0.3 & 0.4 & 0.5 & 0.6 & 0.7\end{array}$

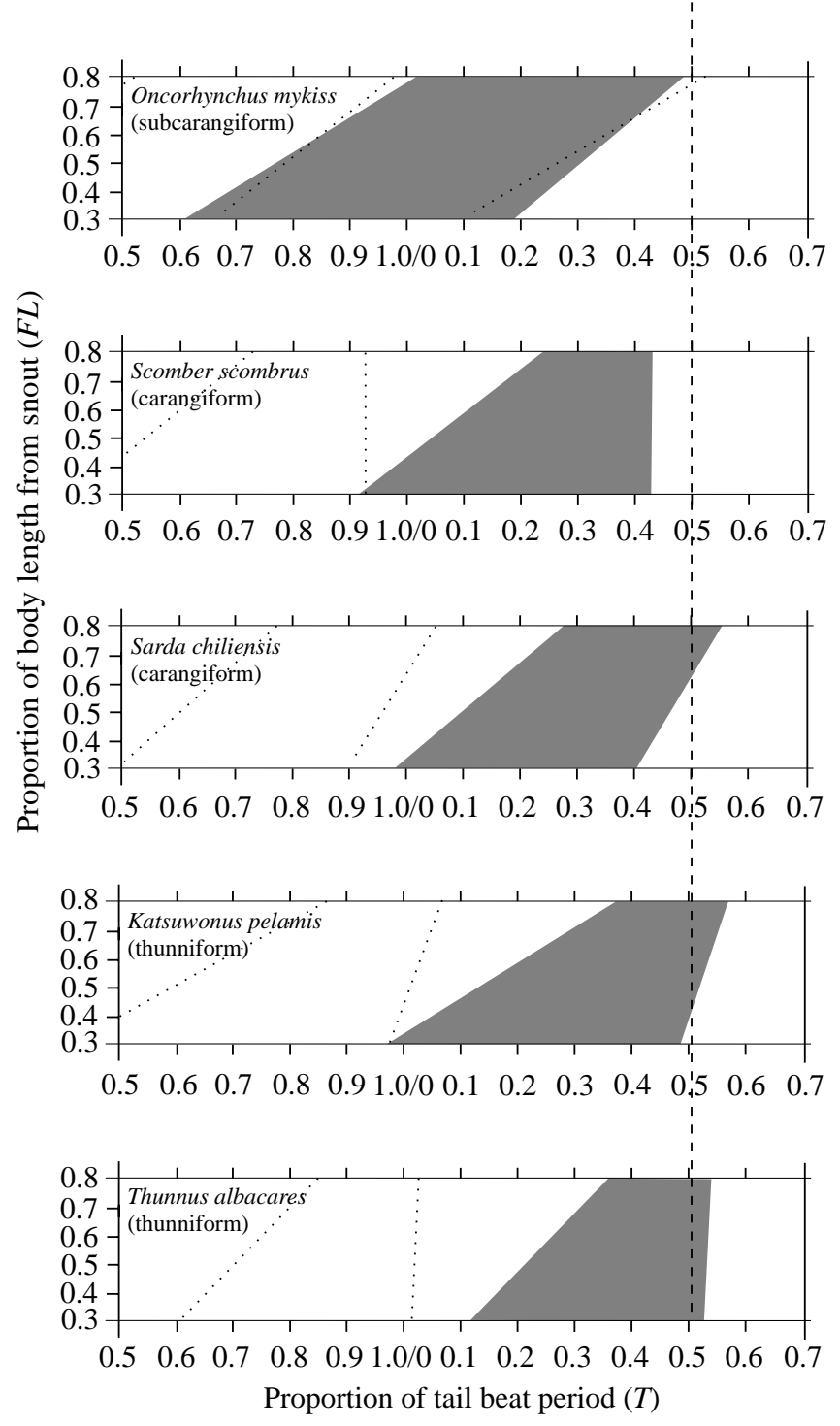

scombrus the overlap is small. EMG activity tends to be increasingly concentrated later in the tailbeat cycle, with offset occurring at around the time of peak force or when the tail tip crosses the swimming track.

The posterior oblique tendons (POTs) are a major means of
Fig. 10. Slow-twitch muscle activity in relation to tailbeat cycle for a range of species representing anguilliform, subcarangiform, carangiform and thunniform swimmers. Activity is scaled relative to a point in the tailbeat cycle, $0.5 T$, where $T$ is the duration of the tailbeat cycle, which represents peak force, or the point at which the tail tip crosses the swimming track towards the active side of the fish. To allow comparison, these two events are assumed to be approximately coincident. This activity is represented by the shaded areas. Contralateral muscle activity is shown by the regions bounded by the dotted lines. Data were derived from the following sources: Anguilla rostrata, Gillis (1998); Oncorhynchus mykiss, Hammond et al. (1998); Katsuwonus pelamis and Thunnus albacares, Knower et al. (1999). $F L$ is the body length from snout to tail fork.

Table 3. Rate of propagation of the wave of muscle activation

\begin{tabular}{lcl}
\hline & $\begin{array}{c}\text { EMG activation } \\
\text { wave speed } \\
\text { Species }\end{array}$ & \\
\hline Thunnus albacares & 2.0 & Kource of EMG data \\
Katsuwonus pelamis & 1.3 & Shadwick et al. (1999) \\
Sarda chiliensis & 1.7 & This study \\
Scomber scombrus & 1.5 & Wardle and Videler (1993) \\
Oncorhynchus mykiss & 1.2 & Hammond et al. (1998) \\
Anguilla rostrata & 0.7 & Gillis (1998)
\end{tabular}

$F L$, fork length; $T$, the duration of one complete tailbeat.

There is a general decrease in propulsive wavelength down the list of species.

power transmission in the scombrid median horizontal septum (Westneat et al., 1993). These tendons extend back diagonally from the posterior lateral extremes of the myotomes and insert on the vertebral column. The arrangement of POTs will determine how muscular contraction is translated into movement of the axial skeleton. Consider a posterior oblique tendon of length $A$. This attaches to the vertebral column at point $X$ and runs through a sling formed by an anterior oblique tendon (AOT) (Fig. 11). The slow-twitch muscle attached to the POT exerts a pull on the tendon, effectively reducing its length as it slides through the sling. The new shorter length is $A_{\mathrm{s}}$. This exerts a lateral pull on the vertebral column, producing a lateral deflection of point $X$, reducing angle $a$ by an amount $\Delta a$ to form angle $a_{\mathrm{s}}$. The lateral displacement of point $X$ is equal to $B \sin \Delta a$.

$$
\sin \Delta a=\left(\sin a-a_{\mathrm{s}}\right)=\sin a \cos a_{\mathrm{s}}-\cos a \sin a_{\mathrm{s}} .
$$

If the situation is simplified by making angle $a$ a right angle prior to any movement of the vertebral column; then, $\cos a=0$,

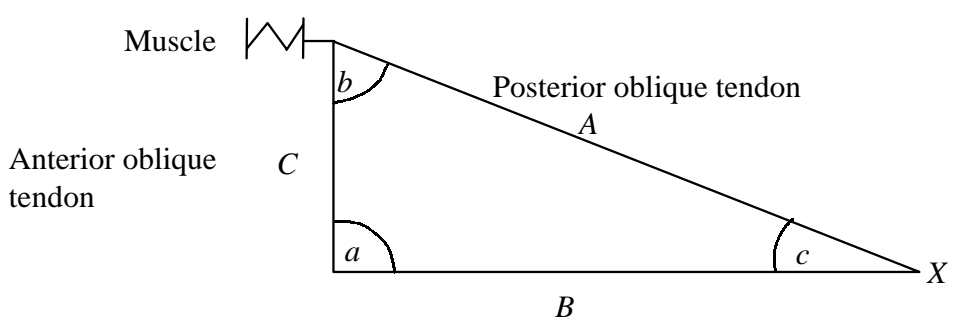

Fig. 11. Schematic diagram of the arrangement of the major tendons in the median horizontal septum of a scombrid fish. See Discussion for further details. 
and $\sin a=1$. The formula for $\sin \Delta a$ becomes simplified to $\sin \Delta a=\cos a_{\mathrm{s}}$.

From the law of cosines:

$$
\cos a_{\mathrm{s}}=\left(\frac{B^{2}+C^{2}-A_{\mathrm{s}}^{2}}{2 B C}\right),
$$

so the lateral displacement $d$ of $X$ is:

$$
d=B\left(\frac{B^{2}+C^{2}-A_{\mathrm{s}}^{2}}{2 B C}\right)
$$

For a given amount of muscular contraction, the degree of lateral displacement of the vertebral column is dictated by two main factors: the distance of the muscle from the vertebral column $(C)$ and the distance along the axis of the fish from the muscle to the point of insertion of the POT $(B)$. In tuna and bonito, the POTs extend back 5-7 vertebrae from their origin at the muscle to their point of insertion. Mackerel have POTs that extend back from the slow-twitch muscle over a smaller number of vertebrae (3-5). This means that the arrangement of POTs in tuna and bonitos is more effective at producing lateral displacement of the vertebral column than the arrangement in mackerel.

The high slow-twitch muscle volume of scombrids relative to most other teleosts is presumably an adaptation for an active, pelagic lifestyle. To accommodate this large volume whilst still placing the muscle close to the tendons that allow efficient power transfer, some muscle must be placed medially along the median horizontal septum. This medial placement of muscle fibres is a likely first step in the evolution of endothermic lateral muscle. Internal placement provides the potential for the development of a small temperature differential between the deep slow-twitch muscle and the surrounding water. The lack of retia mirabilia means that initially this gradient would be small at best, but even a small temperature increase would improve muscle power output.

This research was supported by NSF IBN 9507499 to B.A.B. and the Monterey Bay Aquarium. D.J.E. and J.D.A. were funded by the BBSRC. D.J.E. holds a BBSRC Special Studentship. We are grateful to Chuck Farwell, Andy Seitz, Jeff Morrissette and Dave Marcinek for their assistance and good humour. Thanks are also due to Sippican Ocean Systems for their gift of bathythermograph wire.

\section{References}

Altringham, J. D. and Block, B. A. (1997). Why do tuna maintain elevated slow muscle temperatures: power output of muscle isolated from endothermic and ectothermic fish. J. Exp. Biol. 200, 2617-2627.

Altringham, J. D. and Ellerby, D. J. (1999). Fish swimming: patterns in muscle function. J. Exp. Biol. 202, 3397-3403.

Altringham, J. D. and Johnston, I. A. (1990). Scaling effects on muscle function: power output of isolated fish muscle fibres performing oscillatory work. J. Exp. Biol. 151, 453-467.

Altringham, J. D., Wardle, C. S. and Smith, C. S. (1993).
Myotomal muscle function at different locations in the body of a swimming fish. J. Exp. Biol. 182, 191-206.

Blake, R. W., Chatters, L. M. and Domenici, P. (1995). Turning radius of the yellowfin tuna (Thunnus albacares) in unsteady swimming manoeuvres. J. Fish Biol. 46, 536-538.

Block, B. A. and Finnerty, J. R. (1994). Endothermy in fishes: a phylogenetic analysis of physiological constraints, predispositions and selection pressures. Env. Biol. Fish. 40, 283-302.

Boddeke, R., Slijper, E. J., Stelt, A. and van der, (1959). Histological characteristics of the body musculature of fishes in connection with their mode of life. Proc. K. Ned. Akad. Wet. Ser. C Biol. Med. Sci. 62, 576-588.

Bone, Q. (1966). On the function of the two types of myotomal muscle fibre in elasmobranch fish. J. Mar. Biol. Ass. UK 46, 321-349.

Bone, Q. (1978). Locomotor muscle. In Fish Physiology, vol. 7 (ed. W. S. Hoar and D. J. Randall), pp. 361-424. New York, London: Academic Press.

Brill, R. W. and Dizon, A. E. (1979). Red and white muscle fibre activity in swimming skipjack tuna, Katsuwonus pelamis (L.). $J$. Fish Biol. 15, 679-685.

Carey, F. G. and Lawson, K. D. (1973). Temperature regulation in free swimming bluefin tuna. Comp. Biochem. Physiol. 44A, 375-392.

Collette, B. B. (1978). Adaptations and systematics of the mackerels and tunas. In The Physiological Ecology of Tunas (ed. G. D. Sharp and A. E. Dizon), pp. 7-40. New York, London: Academic Press.

Coughlin, D. J. and Rome, L. C. (1999). Muscle activity in steady swimming scup, Stenotomus chrysops, varies with fiber type and body position. Biophys. J. 196, 145-152.

Dewar, H. D. and Graham, J. B. (1994a). Studies of tropical tuna swimming performance in a large water tunnel. I. Energetics. $J$. Exp. Biol. 192, 13-31.

Dewar, H. D. and Graham, J. B. (1994b). Studies of tropical tuna swimming performance in a large water tunnel. III. Kinematics. $J$. Exp. Biol. 192, 45-59.

Fierstine, H. L. and Walters, V. (1968). Studies in locomotion and anatomy of scombroid fishes. Mem. S. Calif. Acad. Sci. 6, $1-31$.

Fitch, J. E. (1969). Offshore Fishes of California. Fourth revision. Sacramento, CA: California Department of Fish and Game. 79pp.

Frolich, L. M. and Biewener, A. A. (1992). Kinematic and electromyographic analysis of the functional role of the body axis during terrestrial and aquatic locomotion in the salamander Ambystoma tigrinum. J. Exp. Biol. 162, 107-130.

Gillis, G. B. (1998). Neuromuscular control of anguilliform locomotion: patterns of red and white muscle activity during swimming in the American eel Anguilla rostrata. J. Exp. Biol. 201, 3245-3256.

Gillis, G. B. (2000). Patterns of white muscle activity during terrestrial locomotion in the American eel (Anguilla rostrata). J. Exp. Biol. 203, 471-480.

Goldman, D. E. and Richards, J. R. (1954). Measurement of high frequency sound velocity in mammalian soft tissues. J. Acoust. Soc. Am. 26, 981-983.

Graham, J. B., Koehrn, F. J. and Dickson, K. A. (1983). Distribution and relative proportions of red muscle in scombrid fishes: consequences of body size and relationships to locomotion and endothermy. Can. J. Zool. 61, 2087-2096.

Greer-Walker, M. and Pull, G. A. (1975). A survey of red and white muscle in marine fish. J. Fish Biol. 7, 295-300. 
Grey, H. W. (1971). (ed.) California's Living Marine Resources and their Utilisation. Sacramento, CA: California Department of Fish and Game. 148pp.

Griffiths, R. I. (1987). Ultrasound transit time gives direct measurement of muscle fibre length changes in vivo. J. Neurosci. Meth. 21, 159-165.

Grillner, S. and Kashin, S. (1976). On the generation and performance of swimming in fish. In Neural Control of Locomotion (ed. R. M. Herman, S. Grillner, P. S. G. Stein and D. G. Stuart), pp. 181-201. New York: Plenum.

Hammond, L., Altringham, J. D. and Wardle, C. S. (1998). Myotomal slow muscle function of rainbow trout Oncorhynchus mykiss during steady swimming. J. Exp. Biol. 201, 1659-1671.

Hatta, I., Sugi, H. and Tamura, Y. (1988). Stiffness changes in frog skeletal muscle during contraction recorded using ultrasonic waves. J. Physiol., Lond. 403, 193-209.

Hertel, H. (1966). Structure, Form, Movement. New York: Reinhold. 251pp.

Hess, F. and Videler, J. J. (1984). Fast continuous swimming of saithe: a dynamic analysis of bending moments and muscle power. J. Exp. Biol. 109, 229-251.

Jayne, B. C. (1988). Muscular mechanisms of snake locomotion: an electromyographic study of lateral undulation of the Florida Banded Water Snake (Nerodia fasciata) and the Yellow Rat Snake (Elaphe obsoleta). J. Morph. 197, 159-181.

Jayne, B. C. and Lauder, G. V. (1995). Are muscle fibers within fish myotomes activated synchronously? Patterns of recruitment within deep myomeric musculature during swimming in largemouth bass. J. Exp. Biol. 198, 805-815.

Johnson, T. P., Syme, D. A., Jane, B. C., Lauder, G. V. and Bennett, A. F. (1994). Modeling red muscle power output during steady and unsteady swimming in largemouth bass. Am. J. Physiol. 267, 418-488.

Johnston, I. A., Davison, W. and Goldspink, G. (1977). Energy metabolism of carp swimming muscles. J. Comp. Physiol. 114, 203-216.

Knower, T., Shadwick, R. E., Katz, S. L., Graham, J. B. and Wardle, C. S. (1999). Red muscle activation patterns in yellowfin (Thunnus albacares) and skipjack (Katsuwonus pelamis) tunas during steady swimming. J. Exp. Biol. 202, 2127-2138.

Lighthill, M. J. (1969). Hydromechanics of aquatic animal propulsion. Annu. Rev. Fluid Mech. 1, 413-466.

Lighthill, M. J. (1975). Mathematical Biofluiddynamics. Philadelphia, PA, USA: Society for Industrial and Applied Mathematics. 275pp.

Magnuson, J. J. (1973). Comparative study of adaptations for continuous swimming and hydrostatic equilibrium of scombroid and xiphoid fishes. Fish. Bull. 71, 337-356.

Magnuson, J. J. (1978). Locomotion by scombrid fishes. In Fish Physiology, vol. 7 (ed. W. S. Hoar and D. J. Randall), pp. 239-313. New York, London: Academic Press.

Moi, C. R. and Breddels, P. A. (1982). Ultrasound velocity in muscle. J. Acoust. Soc. Am. 71, 455-461.
Rayner, M. D. and Keenan, M. J. (1967). Role of red and white muscles in the swimming of the skipjack tuna. Nature 214, 392-393.

Rome, L. C., Choi, I., Lutz, G. and Sosnicki, A. (1992). The influence of temperature on muscle function in the fast swimming scup. I. Shortening velocity and muscle recruitment during swimming. J. Exp. Biol. 163, 259-279.

Rome, L. C. and Swank, D. (1992). The influence of temperature on power output of scup red muscle during cyclical length changes. $J$. Exp. Biol. 171, 261-281.

Rome, L. C., Swank, D. and Corda, D. (1993). How fish power swimming. Science 261, 340-343.

Rosenberger, L. J. and Westneat, M. W. (1999). Functional morphology of undulatory pectoral fin locomotion in the stingray Taenuria lymma (Chondrichthyes: Dastatidae). J. Exp. Biol. 202, 3523-3539.

Shadwick, R. E., Katz, S. L., Korsmeyer, K., Knower, T. and Covell, J. W. (1999). Muscle dynamics in skipjack tuna: timing of red muscle activation in relation to activation and body curvature during steady swimming. J. Exp. Biol. 202, 2139-2150.

Shadwick, R. E., Steffensen, J. F., Katz, S. L. and Knower, T. (1998). Muscle dynamics in fish during steady swimming. Am. Zool. 38, 755-770.

van Leeuwen, J. L., Lankheet, M. J. M., Akster, H. A. and Osse, J. W. M. (1990). Function of red axial muscles in carp (Cyprinus carpio L.): recruitment and normalised power output during swimming in different modes. J. Zool., Lond. 220, 123-145.

Videler, J. J. (1985). Fish swimming movements: a study of one element of behaviour. Neth. J. Zool. 35, 170-185.

Videler, J. J. and Hess, F. (1984). Fast continuous swimming of two pelagic predators, saithe (Pollachius virens) and mackerel (Scomber scombrus): a kinematic analysis. J. Exp. Biol. 109, 209-228.

Wardle, C. S. and Videler, J. J. (1993). The timing of the electromyogram in the lateral myotomes of mackerel and saithe at different swimming speeds. J. Fish Biol. 42, 347-359.

Wardle, C. S., Videler, J. J. and Altringham, J. D. (1995). Tuning in to fish swimming waves: body form, swimming mode and muscle function. J. Exp. Biol. 198, 1629-1636.

Wardle, C. S., Videler, J. J., Arimoto, T., Franco, J. M. and He, P. (1989). The muscle twitch and the maximum swimming speed of giant bluefin tuna, Thunnus thynnus L. J. Fish Biol. 35, 129-137.

Webb, P. W. (1975). Hydrodynamics and energetics of fish propulsion. Bull. Fish. Res. Bd Can. 190, 1-159.

Weihs, D. (1989). Design features and mechanics of axial locomotion in fish. Am. Zool. 29, 151-160.

Westneat, M. W., Hoese, W., Pell, C. A. and Wainwright, S. (1993). The horizontal septum: Mechanisms of force transfer in locomotion of scombrid fishes (Scombridae, Perciformes). $J$. Morph. 217, 183-204.

Williams, T. L., Grillner, S., Smoljaninov, V. V., Wallen, P., Kashin, S. and Rossignol, S. (1989). Locomotion in lamprey and trout: the relative timing of activation and movement. J. Exp. Biol. 143, 559-566. 